\title{
Jules Michelet y La bruja: entre la bruma de lo visible y la copporeidad del placer de la escritura*
}

\author{
Hilderman Cardona-Rodas \\ Universidad de Medellín, Colombia \\ hcardona@udem.edu.co \\ https://orcid.org/0000-0002-6778-2102
}

\section{RESUMEN}

Este artículo presenta algunas reflexiones sobre el libro La bruja. Un estudio de las supersticiones en la Edad Media publicado por Jules Michelet en 1862, el cual pone en tensión el vínculo entre cuerpo, brujería, transgresión y sacrificio en la figura de la hechicera, comadre o bruja de la Edad Media. Para ello, se recurre a diversos estudios que tienen a esta obra y la bruja como centro de sus intereses reflexivos. En este artículo, una poética del sacrificio que sublima el mal como intensidad de transgresión. La bruja es la mujer que estará parcialmente oculta con todos sus encantos, ostentando un saber-curar desde una botánica de la transgresión. Así, la bruja-víctima que muere en la hoguera muestra el pánico y horror que una cultura hegemónica experimenta ante la cultura popular que se hace cuerpo en el sacrificio en un proceso inquisitorial, ya que la bruja conoce las potencias mágicas del conocimiento que cura o puede matar en el vínculo entre botánica y medicina.

Palabras clave: Jules Michelet; brujería; Edad Media; mal; transgresión.

Cómo citar: Cardona-Rodas, H. (2019). Jules Michelet y La bruja: entre la bruma de lo visible y la corporeidad del placer de la escritura. Ciencias Sociales y Educación, 8(16), 57-72. DOI: https://doi.org/10.22395/csye.v8n16a4 Recibido: 10 de julio de 2019.

Aprobado: 15 de noviembre de 2019. 


\section{Jules Michelet and Witcheraft: Between the Mist of the Visible and the Corporeality of Writing}

\section{ABSTRACT}

This article displays some reflection about the book Satanism and witchcraft; a study in medieval superstition published by Jules Michelet in 1862, which puts into tension the link between the body, witchcraft, transgression, and sacrifice in the figure of the witch and sorceress in the Middle Ages. For that we appeal to diverse studies of this oeuvre and the witch as the center of its reflective interests, thus this article threads a poetic of sacrifice that sublimates Evil as the intensity of transgression. The witch is the woman that will be partially hidden alongside with her enchantments and holding a know-how to cure from a botanic of transgression. Thus, the witch-victim that dies in the firepit displays the panic and terror that a hegemonic culture goes through in the popular culture that is embodied in the sacrifice of an inquisitorial process, given that the witch knows the magic power of healing or killing knowledge and the link between Botanics and medicine.

Keywords: Jules Michelet; witchcraft; Middle Ages; evil; transgression.

\section{Jules Michelet e A feiticeira: entre a neblina do visivel e a corporeidade do prazer da escrita}

\section{RESUMO}

Este artigo apresenta algumas reflexões sobre o livro A feiticeira, publicado por Jules Michelet, em 1862, que põe em tensão o vínculo entre corpo, bruxaria, transgressão e sacrifício na figura da feiticeira, comadre ou bruxa da Idade Média. Para isso, recorre-se a diversos estudos que têm essa obra e a feiticeira como centro de seus interesses de reflexão, estabelecendo, neste artigo, uma poética do sacrifício que sublima o Mal como intensidade de transgressão. A feiticeira é a mulher que está parcialmente oculta com todos seus encantos, ostentando um saber curar a partir da botânica da transgressão. Assim, a feiticeira-vítima que morre na fogueira mostra o pânico e o horror que uma cultura hegemônica experimenta diante da cultura popular que se faz corpo no sacrifício em um processo inquisitivo, já que a bruxa tem consciência das potências mágicas do conhecimento que cura ou pode matar no vínculo entre botânica e medicina.

Palavras-chave: Jules Michelet; bruxaria; Idade Média; mal; transgressão. 


\section{Introducción}

Pocos hombres apostaron con más ingenuidad que Michelet por
unas cuantas ideas simples: para él, el progreso de la verdad
y de la justicia, y el retorno a las leyes de la naturaleza, eran
procesos indefectibles. Su obra es, en ese sentido, un hermoso
acto de fe. Pero, aunque percibió mal los límites de la razón,
las pasiones que se oponen a ella —es la paradoja que me
sorprende-encontraron en él, en algún caso, a un cómplice.

(Georges Bataille, 2010, p. 57)

La obra de Jules Michelet (1798-1874) le apuesta a un proceso de escritura del exceso del significante en los márgenes de la representación, entre la bruma de lo visible y la corporeidad del placer de la escritura que desplaza el sentido cuando interpretar es un invertir. En un poema de Giosue Carducci (1835-1907), a quien se le otorgó el premio nobel de literatura en 1906 y tenía una abierta posición anticlerical, se pone en evidencia esta transustancialización del hecho histórico (que en Michelet tiene resonancias morales y oscila entre el exceso de precisión y el exceso de evanescencia), en pos de una representación "deseada" con una estructura evidentemente poética. El poema se titula A Satanás, donde se realza la figura de Satán, Rey de los fenómenos y de las formas, el Rey del Banquete, el porta-luz de Fausto que transfigura los valores e instituye una historia invertida, al revés la de la transgresión:

A ti de los seres
principio inmenso
espíritu y forma
sentido y credo;
mientras en las copas
destelle el vino
como en las pupilas
fuego divino.
Y mientras sonrían
tierras y soles,
y diálogos haya
de amantes voces;
y el eco estremezca
de himno arcano
los montes, y vibre
fecundo el llano.
A ti yo levanto
mi verso ardiente;
Satán, yo te aclamo
Rey del Banquete.

(Carducci, 1959, p. 19) 
El mismo Carducci nos explica su pathos predicativo:

[...] Hasta donde es posible en un poema lírico, he intentado sintetizar el desarrollo del naturalismo panteísta en política, arte, historia, ciencias y sociedad. Mi propósito ha sido mostrar la abierta rebelión de la naturaleza y de la humanidad contra la opresión del feudalismo dinástico. (Carducci, 1959, p. 19)

En La bruja publicada por primera vez en 1862, encontramos una declaración afín a la de Carducci, cuando Michelet se refiere a ese espíritu invertido, a ese éter sagrado, ese espíritu-símbolo de la naturaleza, vidente de la resurrección del deseo en la Edad Media:

[...] Un azul indefinible, que la rosada aurora respetaba, como si no se atreviere a invadirlo, un éter sagrado, un espíritu hacia toda la naturaleza espíritu [...] Sentíase, sin embargo, un progreso, lentos y dulces cambios. Una gran maravilla iba a venir, a resplandecer y a eclipsarlo todo. Y se la dejará venir sin precipitarla. La próxima transfiguración, las alegrías esperadas de la luz, no quitaban nada al profundo encanto de estar todavía en la sombra divina, medio ocultos, sin desprenderse aún del prodigioso encanto. (Michelet, 1984, p. 331)

Las modalidades enunciativas elegidas por Michelet y Carducci, ponen en escena un deleite de la palabra que hace de la escritura la apertura a una corporeidad del placer de la escritura, a partir de la cual aquello que se dice reverbera en una disposición estética y sensible encarnada en la poesía y en la historia. La escritura de esta forma es recreada por una disposición corporal que teatraliza el mal en las posibilidades creativas de la palabra, la cual se hace carne en las figuras de la hechicera y Satán según sensualidad y placer que se despliegan en una arqueología de la medicina, en el caso de Michelet y que en Carducci se convierte en una inmersión de todos los sentidos en aquello que perturba por su condición transgresora. Esto lo veremos reflejado igualmente en la propuesta estética del pintor inglés William Blake.

Es la bruja la "mártir universal de la Edad Media" europea, la que domina la medicina de la contraciencia de la época: la botánica, arte del conocimiento de la naturaleza, verdadero satanismo, rebelión contra Dios, es decir, contra la enfermedad que azotaba a los humildes, un castigo de Dios. Esta es la mujer que permanecerá en la sombra divina, semioculta, sin desprenderse de su encanto: el saber-curar, es decir, la transgresión. Por ello, "la mujer estará en las ciencias y llevará a ella la dulzura y la humanidad como una sonrisa de la naturaleza" (Michelet, 1984, p. 330). Las comadronas, nombre cortés y tenebroso que se le daba a las hechiceras, dice Michelet, encarnan la medicina popular como sabedoras del poder farmacológico ${ }^{1}$ de las plantas. En la Edad Media una mujer

1 La noción de fármaco viene del griego phármakon ( $\varphi \alpha \hat{\alpha} \mu \alpha \kappa o v)$ y posee un carácter polisémico: alucinógeno, tintura de los pintores, droga curativa, remedio, bebida encantadora o chivo expiatorio. Es un remedio para la vida y, a la vez, veneno para la muerte, remitiendo al aforismo de Paracelso (1493-1541), según el cual "no hay venenos, hay dosis". Desde la perspectiva del chivo expiatorio, podría ser la figura en un rito sacrificial, 
no hubiese permitido que un médico varón tratase sus dolencias, pues serán las hechiceras, más aún en el caso de "enfermedades de las mujeres", quienes cumplirán la función de médico.

Lo que mejor sabemos de su medicina es que para los usos más diversos, para calmar y estimular, empleaba mucho una gran familia de plantas equívocas y muy peligrosas, que rindieron los más grandes servicios. Con razón se les llama las Consolantes (solanáceas). (Barthes, 2004, p. 83)

Según Roland Barthes (1987), en la lectura de Michelet aflora un determinado trastorno de la discursividad. Todas sus figuras reaparecen continuamente, dotadas de los mismos "epítetos de naturaleza", los cuales son producto de una intención que es a la vez corporal y moral. Este aspecto, cuando Michelet narra una historia, no es muy claro en una lectura superficial, debido al encadenamiento de los hechos que escoge el historiador, esto es, se hace enigmático al nivel del discurso. Barthes ve la causa de este trastorno en tres motivos esenciales. El primero que analiza es la discursividad elíptica de Michelet, desde la cual se pone en práctica el asíndeton, la ruptura, el salto de los enlaces por medio de un "estilo vertical". Esto equivale a una estructura errática que privilegia a los enunciados-bloque sin la participación de la visibilidad de los intersticios, por lo que prima en sí una estructura evidentemente poética.

El segundo motivo radica en la enunciación repleta de juicios:

Michelet no expone primero para juzgar a continuación: opera una confusión inmediata, un auténtico aplastamiento, entre lo anotable y lo condenable (o alabable) [...] El relato de Michelet [...] es una narración (mejor sería llamarlo una enunciación) que se injerta sobre un relato subyacente que se supone ya conocido [...] Lo que interesa a Michelet es el predicado, que es lo que añade el hecho (al "tema"). (Barthes, 1987, p. 242)

De allí que para Michelet el discurso no comience con el pleno derecho, sino con el atributo, con lo apreciativo, donde toda gramática es optativa:

[...] el "lirismo" de Michelet proviene menos de su subjetividad que de la estructura lógica de su enunciación: piensa con atributos — predicados— no con entidades, atestiguaciones; y eso es lo que explica esos trastornos de su racionalidad discursiva; el razonamiento, la exposición racional, "clara", consiste en progresar tesis por tesis (de verbo en verbo) y no en desplegar en seguida un torbellino de adjetivos. (Barthes, 1987, p. 243)

donde el otro será sacrificado en beneficio del mismo, en un ciclo de eterno retorno de una culpa de asesinato ritual. Consultar Nietzsche (2009, 2011), Girard (1995) y Cardona (2017). 
El último motivo reside en la concepción misma de hecho que tiene Michelet. Para él lo importante es la resonancia moral del hecho histórico y no su talla. Por ello, el hecho de Michelet oscila entre el exceso de precisión y el exceso de evanescencia, en donde jamás se tendrá su dimensión exacta. El acento de Michelet es puesto en la proporción de los hechos. He aquí un punto en concordancia con Nietzsche, cuando el filósofo afirma que:

[...] No hay hechos en sí. Lo que sucede es un grupo de fenómenos, elegidos y agrupados por un ser que los interpreta [...] No hay un estado de hecho en sí, por el contrario, hay que introducir un sentido incluso antes de que pueda haber un estado de hecho. (Barthes, 1987, p. 244)

Michelet nunca detendrá el lenguaje en el hecho pues "en esa inmensa puesta en escena de una realidad milenaria, el lenguaje precede al hecho hasta al infinito" (Barthes, 1987, p. 244).

La obra del historiador francés no preexistirá a las condiciones de existencia de los enunciados que la expresan y las visibilidades que la ocupan. Michelet, a través del pathos de su época, representó las condiciones reales del discurso histórico. Superó la oposición mítica entre la subjetividad y la objetividad sustituyéndola por la oposición entre el enunciado y la enunciación, esto es, entre el producto de la investigación y la producción del texto en los modos de subjetivación del discurso que se encarne en la escritura de efervescencias narrativas. A partir de este último punto, es necesario tener en cuenta lo que Michelet pretende ver (el referente) y su descripción (el tejido de los significantes), pues a menudo quedará un residuo, un agujero.

Otro punto interesante en la producción de Michelet radica en la apuesta fisiológica que se vislumbra en sus descripciones; él realizará una experiencia sobre su propio cuerpo como si fuera un adicto —nos dice Barthes- al hachís o a la mescalina:

Yo persistía en mi trabajo, con la curiosidad de ver si esa fuerza salvaje conseguiría oprimir, atenazar a un espíritu libre. Mantuve mi pensamiento en actividad, dueño de sí mismo. Iba escribiendo y observándome. Tan solo a la larga fatiga y la privación de sueño llegaron a afectar en mí una capacidad, la más delicada, a mi parecer, en el escritor, que es el sentido del ritmo. Las frases me llegaban inarmónicas. Esa es la primera cuerda que se rompió en mi instrumento. (Michelet, como se citó en Barthes, 1987, p. 246)

La alucinación se abre paso,

[...] me producían el efecto de un espantoso mob, de un horrible populacho, no de hombres, sino de perros ladrando, un millón, mil millones de dogos encarnizados, o más bien, enloquecidos [...] Pero ¿Qué estoy diciendo?, ¿perros, dogos?, ni siquiera eran eso. Eran apariciones execrables e innominadas, animales sin ojos y sin orejas, enteramente hechos de fauces espumeantes. (Michelet, como se citó en Barthes, 1987, p. 247) 
Toda esta preocupación alucinada hace que su discurso funde una corporeidad del placer de la escritura enunciativa donde el deseo busca un sentido narrativo: insertar a los hombres y mujeres del pasado no en una cronología o en una razón, sino en una red de comportamientos carnales, en un sistema de medicalización y prácticas de representación y estructuras míticas. Con Michelet se devela la sensualidad de la historia — dice Barthes—, donde el cuerpo se convierte en el fundamento del saber y del discurso, del saber como discurso.

Un exceso del significante en los márgenes de la representación, como se mencionó unas páginas atrás, hace que el discurso de Michelet inaugure una ciencia del desplazamiento (entstellungwissenschaft), si se quiere simbólica. Las operaciones de desplazamiento se logran por la sustitución, la equivalencia simbólica, la cual es una vía sistemática de conocimiento donde este se encuentra en la estructura misma del lenguaje. Las operaciones de desplazamiento de Michelet en favor de una propia dinámica fisiológica de deseo enunciativo, hacen de nuestro autor el hombre del parti pris. Escribir es asumir una posición, tomar partido, donde interpretar es invertir:

[...] Todo discurso procede claramente de una opción, de una evaluación del mundo, de las sustancias, de los cuerpos; no hay hecho que no esté precedido de su propio valor: el sentido y el hecho se dan al mismo tiempo, proposición insólita ante los ojos de la ciencia. (Barthes, 1987, p. 257)

Es evidente una superficie enunciativa en los textos de Michelet, donde presenciamos discriminaciones, fragmentaciones de discurso, distribuciones regidas bajo la ley del placer: una etnografía de la emotividad discursiva. En palabras de Georges Bataille (2010), Michelet observa por medio de la figura del aburrimiento, el achatamiento de los valores. Él sacude obstinadamente el valor "como una especie de llama apocalíptica, pues la idea más moderna -idea que comparte precisamente con Nietzsche y Bataille- es que estamos al final de la Historia (...) Esta idea candente es peligrosa" (Barthes, 1987, p. 257).

La aparición de La bruja convertirá a Michelet en uno de los autores que con más humanidad han hablado del mal. Tal preocupación por el mal en tanto dispositivo enunciativo no ha de ser entendida como el abuso de la fuerza en el cuerpo de los débiles, sino aquel mal exigido por un deseo desenfrenado de libertad que va en contra del propio interés. Pues Michelet:

[...] Intentó legitimarlo cuando le era posible: la bruja era la víctima y moría en el horror de las llamas. Era natural invertir los valores de los teólogos. ¿No se hallaba el Mal del lado del verdugo? La bruja encarnaba a la humanidad sufriente, que los fuertes perseguían. (Bataille, 2010, p. 57)

Lo que guiaba a Michelet era el vértigo del mal, una sensibilidad del extravío. Bataille tratará de demostrar, siguiendo y percibiendo los resortes de 
sensibilidad y visibilidad extraviados de La bruja de Michelet, que la mujersímbolo, hechicera-sacrificio manifiesta el deseo de elevarse y triunfar sobre la muerte o el deslizamiento-pánico sobre la muerte que evidencia el horror y la angustia hacia la muerte:

Lo mismo que algunos insectos en condiciones determinadas, se dirigen juntos hacia el foco de luz, nosotros nos dirigimos todos a la parte opuesta a una reunión donde dominaba la muerte. El resorte de la actividad humana es por lo general el deseo de alcanzar el punto más alejado posible del terreno fúnebre (que se caracteriza por lo podrido, lo sucio, lo impuro): por todas partes borramos las huellas, los signos, los símbolos de la muerte a costa de incesantes esfuerzos. Llegamos a borrar incluso, si es posible, las huellas y los signos de esos esfuerzos. Nuestro deseo de elevarnos no es más que un síntoma, entre cientos, de esa fuerza que nos dirige hacia las antípodas de la muerte. El horror que experimentan los ricos ante los obreros, el pánico que sienten los pequeños burgueses ante la idea de caer en la condición obrera procede del hecho de que a sus ojos los pobres están más cerca que ellos de la guadaña de la muerte. Y a veces esos caminos turbios de la suciedad, de la impotencia, del lodazal, que se deslizan hacia la muerte son más aún objeto de nuestra aversión que la misma muerte. (Bataille, 2010, p. 59)

Todas nuestras concepciones generales de la vida son reductibles al deseo de durar. Michelet participará de tal deseo de preservación en un momento donde la Revolución Industrial se encuentra en su apogeo, cuando máquina y hombre se encuentran en tensión, además del enfrentamiento entre saberes primigenios con el desarrollo de la medicina decimonónica.

La hechicera, dama de la transgresión, al menos durante la Edad Media, fue la artífice de tal deslizamiento sobre la muerte, eleva la resurrección del deseo de los miserables, quienes dominados por la enfermedad veían cómo sus cuerpos se desmoronaban por el dolor. Vieron en la bruja, en la biblia y en sus hierbas la fuente medicamentosa de la salvación que borra los síntomas de la muerte. Algunos apartes de Michelet así nos lo revelan:

La naturaleza las hace hechiceras — a las mujeres-. Es el genio propio de la mujer y su temperamento. Ella nace hada. Mediante el retorno regular de la exaltación, nace sibila. Por amor es maga. Por su finura, por su malicia (con frecuencia fantástica y bienhechora), es hechicera y embruja o cuando menos adormece y engaña a los males [...] iSencillo y conmovedor principio de las religiones y de las ciencias! Después de todo se dividirá: se verá nacer al hombre especial, juglar, astrólogo o profeta, nigromante, sacerdote, médico... pero, en un principio, la mujer lo es todo [...] Así, para las religiones, la mujer es madre, solícita nutriz y guardadora fiel. Los dioses son como los hombres: nacen y mueren en su seno. (Michelet, 1984, pp. 21-22)

Vemos aquí cómo en la Edad Media, época obliterada, el nombre de la hechicera se asocia a la corriente de las ciencias benéficas de la naturaleza.

Los ritos de brujería pertenecen a las distribuciones existenciales de los oprimidos, es su epistemo-gramática, su agenciamiento práctico de saber en 
tanto dispositivo encarnado como enunciado y visibilidad. Los ritos nocturnos del medioevo evocan la religión de los antiguos ${ }^{2}$ que para Bataille son ritos de pagani, de campesinos, de esclavos, de víctimas de un orden normativo y una autoridad de la religión dominante. Los ritos de aquelarres, inversiones del tema cristiano, tendrán como principal figura a las mujeres, las cuales ensalzarán una parodia del sacrificio cristiano: la misa negra como rito invertido que vincula la danza como acto ritual por excelencia, frente al hieratismo de la misa católica que es evidente igualmente en el arte religioso. He aquí la conexión con la corporalidad cuando la danza y el aquelarre se hacen motivo mítico ritual en las técnicas del éxtasis, que las brujas ponen en juego al mezclar botánica y naturaleza en sus filtros mágicos que tienen como objetivo la curación ${ }^{3}$.

El capricho, la dulzura femenina, iluminan el imperio de las tinieblas; algo de la bruja, como contrapartida se une a la idea [...] de la seducción. La exaltación de la mujer y el amor que sustenta hoy nuestras riquezas morales, no se deriva solo de las leyendas de caballería, sino también del papel que desempeñó la mujer en la magia: "por cada brujo, diez mil brujas [...]"4 y les esperaba la tortura, las tenazas, el fuego. (Bataille, 2010, p. 66)

2 En este contexto simbólico e histórico medieval, Satán (re)presenta un Dionisus redivivus, reivindicado desde una relación con la emulación, sin encadenamiento y sin proximidades, que pone en escena la práctica enunciativa del rito.

3 Esta corporalidad que vincula danza y aquelarre está presente en el capítulo XI del libro La bruja de Michelet, denominado "La comunión de revuelta. Los aquelarres. La misa negra", donde el historiador francés sostiene que "esta danza, este frenesí giratorio, la famosa ronda del Aquelarre bastaba para completar este primer grado de embriaguez. Giraban espalda contra espalda, los brazos hacia atrás, sin verse; pero a menudo las espaldas se tocaban. Poco a poco nadie se conocía, ni a la que se tenía al lado. La vieja entonces ya no lo era. Milagro de Satán. Ella era todavía mujer y deseable, confusamente amada" (Michelet, 1982, p. 146), lo cual devendrá en una confusión de fuerzas, en una transustanciación que parodia el sacrificio cristiano que hace emerger al demonio al vaivén del cuerpo que lo convoca. Esto es apreciable en el cuadro del pintor español Francisco de Goya y Lucientes (1746-1828) llamado El aquelarre (1798), en el que con una luna en creciente iluminando la escena, un macho cabrío oficia el aquelarre en el centro de la composición, rodeado por una serie de brujas que ofrecen niños al demonio. Al fondo se ven tres niños colgados de una barra, afianzado con ello el rito sacrificial que entraña la misa negra.

4 La imaginación es moneda corriente al interpretar las fuentes históricas, la cual resulta importante cuando se intenta comprender la tradición oral donde se condensa cómo fue percibido el mundo por hombres y mujeres en el pasado. Así, durante largo tiempo se ha afirmado que fueron millares las personas torturadas y asesinadas por la Inquisición (siglo XII al XV) acusadas de brujería, en su mayoría mujeres. En la brujería perviven prácticas y creencias precristianas metaforizadas por los teólogos inquisitoriales, lo cual revela las mentalidades populares bajo la mirada que aniquila la vista del orden eclesiástico. El recurso a la tortura muestra cómo se proyectan mundos imaginarios en una lógica anatomopolítica del miedo, pues cuando a una persona se lo somete a estos vejámenes termina confesando aquello que los jueces quieren oír. En este sentido, Emmanuel Le Roy Ladurie (1984) criticará la imprecisión con que se ha manejado el número real de casos registrados por los jueces, desde antes de los siglos XIV y XV, acerca de procesos de brujería y la proporción de ejecuciones ligadas a estos procesos, cifras que dan una visión parcial del problema e inexactas reunidas por historiadores como Robert Muchembled (2002): "vemos ya que nos encontramos lejos del «millón de brujas quemadas o matadas", fantástico número que autores, por lo demás bien inspirados, han adelantado a veces para mejor justificar la tesis (incontestable) que las mujeres se vieron con frecuencia oprimidas a lo largo de la historia" (Ladurie, 1984, pp. 13-14). 
Según Bataille, la falla de Michelet es haber convertido a la bruja en la servidora del bien sacándola con ello de su "desgracia". "Ouiso legitimarla atribuyéndole una utilidad, en realidad lo auténtico de sus obras la sitúa al margen" (Bataille, 2010, p. 67). Michelet se mantendrá en el equívoco al conceder al mundo que presentaba un carácter mucho más que de rebeldía, intentando asegurar un porvenir, una pervivencia. La bruja arde en una turbia pasión en Michelet, es su sentimiento-fuerza, su intensidad en los límites del desfallecimiento, limitando las libertades de las trayectorias de las condiciones de posibilidad y de sentido que ordenaban la luminosidad del mundo que intentó vislumbrar. Estamos ante aquel trastorno de discursividad por el exceso del significante en los márgenes de la representación, debido a lo que Michelet pretendía ver (el referente) y su descripción (el tejido de los significantes) ya mencionado, argumento del presente texto.

En La bruja Michelet construye una arqueología de la medicina, de la taxonomía vegetal, nos declara Michel Serres (1996). En esta obra Michelet pretende ser el brujo de su bruja. "Eliminando el genitor, suprimimos el genitivo, es decir, la mujer" (Serres, 1996, p. 267)5. Dice Michelet: "cuando irrumpe, la bruja no tiene padre, ni madre, ni hijo, ni esposo, ni familia: es un monstruo, un aerolito, venido de no se sabe dónde" (Michelet, 1984, p. 28). Este es el sublime poder, su facultad: la bruja tiene una concepción solitaria, ella es primitiva, es unidad original de los pueblos (partenogénesis), de las ciencias (concepciones del espíritu) y de las religiones (de Satán, "filosofía perversa"). Estas singularidades se encuentran en concordancia con el proyecto romántico decimonónico desde donde saborea Michelet: "[...] Exponer la totalidad del devenir, poner al desnudo el original, el suelo primigenio virginal, proyecto que define el mito mismo, la contra ciencia o la no cientificidad, para nosotros y para las otras culturas" (Serres, 1996, p. 268).

Para Michelet, el origen radical es el útero, el tabernáculo, partenogenético donde la causa sui permanezca sin precesión: Eva, pasada, presente y futura, profeta en el espacio desolado del silencio. En el orden de Satán es santa, bella como el diablo y arcaicamente joven, a ella la fiera le indujo el saber.

William Blake (1757-1827) pintó El gran dragón rojo y la mujer revestida en sol (figura 1), en la que da vida a una puesta en escena onírica de un pasaje del apocalipsis, un dragón de siete cabezas y diez cuernos arrastra con su cola la tercera parte de las estrellas y las deposita en la tierra ante una mujer embarazada que al momento de dar a luz devora a su hijo. Aquí la oscuridad de las tinieblas serpentea ante la luz del tabernáculo del conocimiento, vinculación del dragón con la mujer en una escena de canibalismo mítico en el sacrifico ritual de un aquelarre simbólico.

5 Cf. traducción de Luis Alfonso Paláu Castaño, 1993. 

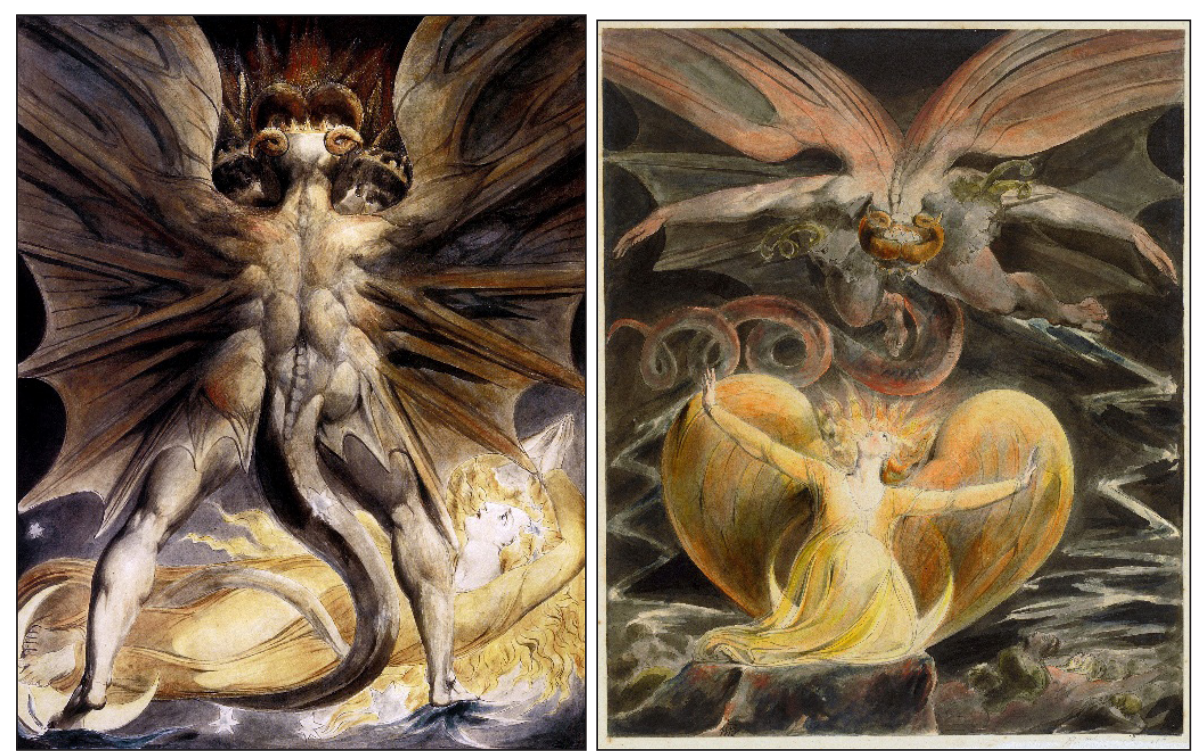

Figura 1. El gran dragón rojo y la mujer revestida en sol Fuente: Blake (1803-1805).

$\mathrm{Al}$ depositar las estrellas en la tierra, otorga una ofrenda a la crueldad del corazón humano que es forjado por el hierro que desgarra la condición sufriente de otro infame que ha de ser sacrificado: la bruja. Así, Blake (1794) traza la imagen divina en un poema:

Una imagen divina.

La crueldad tiene corazón humano

y la envidia humano rostro;

el terror reviste divina forma humana

y el secreto lleva ropas humanas.

Las ropas humanas son de hierro forjado,

la forma humana es fragua llameante,

el rostro humano es caldera sellada

y el corazón humano, su gola hambrienta. ${ }^{6}$

La bruja es el péndulo de una serie de inversiones del saber, se describe, es vivido y asumido como una transgresión donde la ciencia no es otra cosa que la contraciencia. Se trata de una historia de las ciencias: la historia natural, es decir, la botánica y la medicina. Michelet construye en La bruja una física o una filosofía de la naturaleza que devela las condiciones de emergencia del espíritu científico, condiciones de naturaleza social, psicológica, económica, enterradas en el espacio de lo prohibido. "La bruja es [...] una psicoanalista

6 Poema disponible en: http://amediavoz.com/blake.htm\#UNA\%20IMAGEN\%20DIVINA 
de conocimiento objetivo, génesis del saber positivo: la formación del espíritu médico" (Serres, 1996, p. 270). Michelet intentará buscar las condiciones genéticas de la formación del espíritu médico, mientras bucea en tres direcciones: en los basamentos psicoanalíticos, en las infraestructuras socioeconómicas y en los temas genealógicos de la transvaloración nietzscheana. Se construye un tricordio argumentativo: Edipo, la lucha de clases y el dionisismo del Sabbath (Freud-Marx-Nietzsche, aunque trate de objetarse la no continuidad de los autores, legitimación y parentesco de estatutos de escritura, con Michelet). Así "La bruja es y no es La ciencia de los sueños, o Moisés, El capital o El manifiesto, El nacimiento de la tragedia o La gaya ciencia" (Serres, 1996, p. 271). La obra puede ser objeto de tres métodos de lectura o resumir el romanticismo: el secreto no está por debajo sino al lado, no está oculto o por descubrir, está invertido y hay que darle vuelta, un romántico diría que interpretar es invertir.

Esta es la serie que sigue el libro de parte a parte: hombre y mujer, sí y no, noche y día, amanecer y atardecer, fuera y dentro, lo alto y lo bajo (e incluso lo muy alto y lo muy bajo), lo puro y lo impuro, el bosque y el impase, los nómadas y los sedentarios (amurados), la Sorbona y Toledo (universidad diabólica), Dios y Satán, la palabra y el silencio, la naturaleza y la antinaturaleza, la nueva Iglesia reverso de la otra y sus sacramentos a la inversa, la medicina y la ciencia al revés, la vida y la muerte, el remedio y el veneno, etc. (Serres, 1996, pp. 271-272)

Estas series pueden ser descifradas con tres claves: la antítesis retórica, la alienación dialéctica y una teomaquia mítica o la transgresión del psicoanálisis.

Cuando la hechicera, la mujer-símbolo dice: "ya no me pertenezco" (Michelet, 1984, p. 77), esta mujer primitiva es sujeto del saber-transgresión y objeto de la cadena significante del intercambio. Suprime con ambos movimientos el yo, atributo esencial del Mismo. El Otro toma su lugar, este estará provisto del atributo esencial inverso: la nada del yo (Serres, 1984). Al matar al mismo, se mata por consiguiente al yo. En esto consiste la historia a la inversa construida por Michelet.

La contra-ciencia no tiene sujeto; su sujeto ya no es más que el conjunto de claves, la tela de Penélope donde los objetos son recogidos, circulan y constituyen el mundo del sentido. Es de rigor que al cabo del itinerario desaparezca el Ego. Que nuestra modernidad crea tener la elección, puede ser. Que la situación no es nueva, es evidente. $\mathrm{Al}$ cabo de la transgresión queda la muerte del padre y la divinización del Hijo, las palabras renuevan la instancia urdida sobre el monte Citereo; queda la muerte del Hijo, el hombre-dios, queda el complejo de Isaac, es la instancia tramada sobre el monte Morija: el carnero-sustituto tiene los cuernos enganchados en el matorral. De hecho, la situación renace: en la tensión entre cierto helenismo y cierto judaísmo, debe abrir la nueva cientificidad. Es urgente, es vital para la filosofía que el siglo XIX nos sirva al fin de una nueva Edad Media. El nuevo Renacimiento está por darse'. (Serres, 1996, pp. 274-275)

7 Serres afirmaría que es urgente que la historia de las ideas, de los conceptos y de las prácticas discursivas 
Para terminar el presente artículo, analicemos grosso modo, otros dos modos discursivos de abordar el universo de los hechos en torno a la brujería: las explicaciones de Carlo Ginzburg (1994, 1998) y Michel Foucault (1990). Recordemos el teorema de Foucault:

[...] Cada cultura define de una forma propia y particular el ámbito de los sufrimientos, de las anomalías, de las desviaciones, de las perturbaciones funcionales, de los trastornos de conducta que corresponden a la medicina, suscitan su intervención y le exigen una práctica específicamente adaptada. (Foucault, 1990, p. 25)

La práctica de la brujería se encuentra inherentemente relacionada con el estrato o formación histórica en la cual se la enmarque, que se hace visible a partir de un régimen de enunciación característico de cada estrato. La tesis de Carlo Ginzburg la podemos sintetizar por medio de unas líneas de Le Roy Ladurie (1984): "la brujería [...] existió siempre como un instrumento benigno o maligno destinado a manipular el mundo campesino o por medio del que tal mundo se imaginaba manipulado" (p. 13). Ginzburg descubrió entre los campesinos y los medio brujos del Friuli al noroeste de Italia, los cuales conformaban una secta agraria llamada benandanti en el siglo XVI, los restos de un antiguo culto a la fertilidad sin nada de cristiano; este culto se extendía desde los países bálticos hasta las regiones latinas y esclavas de la Italia del nordeste. Este culto agrario en la región italiana de Friuli se dio entre los siglos XVI y XVII, siendo sus practicantes asimilados por los inquisidores a brujos. Este hallazgo le llevará a afirmar que:

[...] Los brujos, los herejes y antes de ellos los leprosos y los judíos (en la Francia del siglo XIV), que eran considerados como enemigos del cristianismo, eran sistemáticamente acusados de complot por las autoridades eclesiásticas y laicas. Estos complots eran en realidad imaginados por las autoridades que arrancaban pruebas falsas a los acusados. Los relatos de aquelarres que aquellos "consentían" en confesar bajo la tortura solo respondían a los deseos y a los miedos de los jueces, y eran realmente las manifestaciones de un complot real por parte de aquellos que detentaban el poder. (Ginzburg, 1998, p. 93)

En este sentido, la creencia en "las batallas nocturnas" libradas entre brujos antagonistas, los que representaban el bien y los que representaban el mal, está vinculada a un rito de estimulación o destrucción de las cosechas, un rito de la fertilidad, a la vez que evoca un culto antiguo a los muertos que no tiene nada que ver con el cristianismo oficial, lo cual le daría la categoría de maléfico y pagano. Los benandanti, los brujos buenos, se enfrentaban a los brujos malos para garantizar la fertilidad de las cosechas y las vendimias, para ello estos "seducen o reprimen a los poderes macabros, maléficos que actúan del Más Allá y que podían destruir las plantas cultivadas" (Ladurie, 1984, p. 16). El modelo

demuestren cuáles son las reales connotaciones que tienen los arquetipos de pensamiento de cada formación histórica, tarea que ha sido tratada muy tangencialmente por la historia académica. 
de Ginzburg corresponde más a prácticas antiguas de brujería situadas en la Edad Media o incluso a una antigüedad salvaje que no termina de expirar, pues Ginzburg encuentra puntos de filiación, núcleo folklórico profundo que ligan los aquelarres a ritos y prácticas simbólicas de la muerte más antiguas que el cristianismo.

Es necesario advertir que aquel núcleo folklórico profundo se pone en juego en la cultura hegemónica medieval, dejando ver una convergencia con la cultura popular en los procesos inquisitoriales por brujería, que derivó en legitimaciones de la violencia expresadas en y sobre los cuerpos. Así lo manifiesta Guinzburg (1994) cuando evoca sus investigaciones sobre procesos de brujería entre los siglos XVI y XVII:

Quería saber qué había representado en realidad la brujería para sus propios protagonistas: las brujas y los brujos; pero la documentación con que contaba (los procesos, y no digamos los tratados de demonología) constituía una barrera tan impenetrable que ocultaba irremediablemente el estudio de la brujería popular. A cada paso tropezaba con los esquemas de origen culto de la brujería inquisitorial. La única brecha en el obstáculo fue el descubrimiento de un filón de creencias hasta entonces ignoradas, y centradas en los benandanti. La discrepancia entre las preguntas de los jueces y las respuestas de los acusados — discrepancia que no podía achacarse ni al trauma del interrogatorio ni a la tortura - traslucía un profundo núcleo de creencias populares sustancialmente autónomas. (p. 8)

Michel Foucault procurará restituir en el interior de cada formación social el proceso que constituye un saber, entendido este como el espacio de las cosas a conocer, suma de los conocimientos efectivos, instrumentos materiales o teóricos que lo sostienen. La brujería y la posesión serán comprendidos como casos patológicos objeto de una práctica médica.

El problema que yo planteo es más bien cómo los personajes de los brujos o poseídos que estaban perfectamente integrados, incluso en estos rituales que los excluían y los condenaban, pudieron convertirse en objeto de una práctica médica que les confería un estatuto muy diferente y los excluyó insertándolos en otro mundo. La base de esa transformación no hay que buscarla en un progreso de la ilustración, sino en el juego de los procesos propios de una sociedad. (Foucault, 1990, pp. 27-28)

Foucault analizará seis personajes en esta comedia humana: el juez, el cura, el fraile, el obispo, el rey, el médico. El médico pretenderá hacer ver que la acción "satánica" tendrá como principal centro al cuerpo, los humores y las mentes de los sujetos más frágiles (ignorantes, doncellas, viejos cascarrabias), obnubilándolos y haciéndoles creer que estaban en presencia del Sabbat donde se adoraba a la Bestia inmunda.

Los casos de brujería acaecidos en el siglo XVII tendrán como principal figura a los sacerdotes, el cual ya a finales del Renacimiento en la conciencia 
popular, había adquirido poderes extraordinariamente ambiguos: la ambivalencia sagrada del sacerdote, donde participan a la vez lo divino y lo demoniaco.

La conciencia civil de la burguesía administrativa sacrificó con gusto el equívoco esencial de esos poderes en nombre de la razón de Estado: el poder del sacerdote debía de quedar privado de sus peligrosas armas; era preciso que se redujese, se simplificase y entrase en armonía con el bien de la sociedad. (Foucault, 1990, p. 35)

Así, la brujería será considerada únicamente en relación con el orden del estado moderno, negando su eficacia pero castigando su intención y desorden por su deslizamiento al mundo moral y social.

\section{Conclusiones}

Después de una travesía reflexiva sobre la figura medieval de la hechicera, la brujería, el sacrificio y la transgresión, teniendo como horizonte discursivo al libro La bruja de Michelet. Es pertinente subrayar que durante la Edad Media se superponen la cultura hegemónica y la cultura popular, puestas de manifiesto en los procesos por brujería a mujeres por la inquisición entre los siglos XII al XV en Europa. La obra de Michelet expone un proceso de escritura donde el exceso del significante se lleva a cabo en los márgenes de la representación de aquello que se ve y se dice en la corporeidad del sentido de la transgresión, donde interpretar es invertir, es decir, percibir lo insólito del acontecimiento que se agita en el sacrificio del chivo expiatorio escenificado en la bruja-víctima quemada.

La bruja pone en juego un psicoanálisis del conocimiento objetivo, evocando los trabajos de Bachelard (2000) sobre la formación del espíritu científico que implementa Serres en sus reflexiones sobre la obra del historiador francés, en términos de una arqueología de la medicina en su vínculo con la botánica, la herbolaria en los usos que la hechicera hace de las plantas como fármacos que curan o pueden causar la muerte. La bruja lee los cuerpos, los signos corporizados como símbolos, y enseña a interpretar en función de las condiciones secretas de un saber-curar de la transgresión, lo cual le significará la muerte como chivo expiatorio en el rito sacrificial de la razón de una cultura hegemónica que ve en la cultura popular el foco de la perdición deseada.

Un ejemplo de escritura que palpita en tanto sentimiento de fuerza y temperamento de la palabra en Michelet, lo constituye la anécdota que relata Bataille (2010) sobre el historiador francés cuando le faltaba la inspiración: salía de su casa en dirección a una cloaca o edículo de olor nauseabundo y sofocante, donde aspiraba profundamente hasta "haberse aproximado lo más cerca que le era 
posible al objeto de su horror" (p. 69), llegando a un estado de estremecimiento y excitación para captar la lógica sacrificial que hacen del cuerpo el lugar del vínculo con lo social ante la ferocidad propia de la ignorancia.

\section{Referencias}

Bachelard, G. (2000). La formación de espíritu científico. Contribución a un psicoanálisis del conocimiento objetivo. Buenos Aires: Siglo XXI Editores.

Barthes, R. (2004). Michelet. México: Fondo de Cultura Económica.

Barthes, R. (1987). El susurro del lenguaje. Más allá de la palabra y la escritura. Barcelona: Paidós.

Bataille, G. (2010). La Literatura y el Mal. Madrid: Taurus.

Blake, W. (1794). Una imagen divina. Recuperado de http://amediavoz.com/blake.htm\#UNA\%20 IMAGEN\%20DIVINA

Blake, W. (1803-1805). El gran dragón rojo y la mujer revestida en sol. Museo de Brooklyn y Galería Nacional de Arte, Washington. Recuperado de https://www.nga.gov/collection/art-objectpage.11502.html; https://www.brooklynmuseum.org/opencollection/objects/4368

Cardona Rodas, H. (2017). El cuerpo como territorio de afirmación política en el dispositivo fotográfico. En N. Cabra y C. Aschner (eds.), Saberes nómadas. Derivas del pensamiento propio (pp. 279-294). Bogotá: Ediciones Universidad Central.

Carducci, G. (1959). Giosue Carducci: seleccion y edicion. Bogotá: Iris.

Foucault, M. (1990). Médicos, jueces y brujos en el siglo XVI. En M. Foucault, La vida de los hombres infames. Madrid: La Piqueta.

Ginzburg, C. (1998). El brujo, el juez y el historiador. Sociología. Revista de la Facultad de Sociología de Unaula, 21, 91-95.

Ginzburg, C. (1994). El queso y los gusanos. El cosmos, según un molinero del siglo XVI. Barcelona: Muchnik Editores.

Girard, R. (1995). La violencia y lo sagrado. Barcelona: Anagramas.

Ladurie, E. (1984). La bruja de jazmín. Barcelona: Argos Vergara.

Michelet, J. (1984). La Bruja. Barcelona: Labor.

Muchembled, R. (2002). La historia del diablo. Siglos XII-XX. México: Fondo de Cultura Económica.

Nietzsche, F. (2009-2011). Nietzsche I y II. Madrid: Editorial Gredos.

Serres, M. (1996). Traducción tesis por tesis: La bruja. En M. Serres, La comunicación. Hermes I. Barcelona: Anthropos. 